\title{
Riesgo, tecnociencia y biotecnología ${ }^{1}$
}

\author{
Francisco Javier Tirado \\ Universitat Autònoma de Barcelona \\ franciscojavier.tirado@uab.es
}

\section{Introducción}

Me gustaría comenzar la conferencia leyendo una conversación. Ésta me permitirá presentarme e introducir el tema de esta sesión. Aquí la tenemos, no voy a dar ningún tipo de indicación o contexto porque ya veréis que se producirá sobre la marcha:

1. c: Pero es transgénica o no?

2. v: no...no...

3. c:... ja emmm... pero es que no sé...

4. v: qué más te pongo?

5. c: $300 \mathrm{gr}$. De garbanzos... es que en el herbolario me la venden en unas bolsitas individuales con una etiqueta que dice que es biológica...

6. (la vendedora sale de detrás de la mesa y llena una bolsa con garbanzos que hay en un saco, mira a la clienta mientras los sirve)

7. v: ya... pero es la misma soja que tengo yo aquí

8. c: no sé... ay... mira que vengo de allí y me he olvidado...

9. c: y lentejas...

10. v: cuántas quieres??

11. c: también 300 gramos

12. (vuelve a salir de detrás de la mesa y se acerca a otro saco)

13. v: de cuáles quieres??

14. c: qué tienes??

15. v: de zaragoza y las rojas que vienen de fuera...

16. c: las de aquí... mejor...

17. (la vendedora pone las lentejas y la clienta mira el saco de soja atentamente)

18. v: mira... la soja llega al puerto en grandes cargamentos y es toda la misma. Llega en grandes sacos que luego se distribuyen. Los sacos que nosotros tenemos llevan esa etiqueta biológica que tú dices...

19. c: ya... pero es que quiero más información porque no quiero comer soja transgénica...

\footnotetext{
${ }^{1}$ Conferencia dictada el 21 de Febrero de 2003 en la Universidad de la Laguna en el marco del curso de especialización Políticas Públicas Ambientales e Investigación Interdisciplinar
} 
20. v: mira, si tampoco podemos saberlo, está toda mezclada... la soja se utiliza para muchas cosas: hacen la leci... cómo se dice?? La leci... emm...

21. c: la lecitina de soja

22. v: sí, eso mismo, y la ponen en chocolates, galletas y miles de cosas que nos comemos cada día...

23. c: yaaa!! Claro, por eso yo la compro en las bolsitas que dice que es biológica y llevan la etiqueta...

24. v: yo te aseguro que es la misma...

25. (el tono de la vendedora se ha elevado, parece irritada)

26. v: en esta casa hace más de 100años que cuidamos a los clientes y vendemos los productos más naturales y con mayor calidad... y si no quieres nuestra soja cruza la calle y cómprala en el herbolario... no pasa nada... qué más quieres guapa?

27. c: berberechos... mira yo no pongo en duda lo que vendes, ni calidad ni nada... pero el tema de los transgénicos es más importante de lo que te crees... yo hablaba de informarnos de los productos...

28. v: sí, a mí que me explicas, ya vinieron los de TV3 a preguntar por la soja... y es que es toda la misma...

29. c: mira, no me la quedo (la soja)

30. v: María, puedes cobrar a la chica

Soy un investigador que pertenece a un grupo de la UAB que se llama Grupo de Estudios Sociales en Ciencia y Tecnología, GESCIT. Y he querido arrancar esta sesión con la trascripción de la anterior conversación porque ilustra perfectamente el principal interés de este grupo: la relación entre tecnociencia, entre productos tecnocientíficos y nuestra vida cotidiana. Es decir, analizamos el impacto, las transformaciones que los elementos tecnocientificos generan en nuestra cotidianidad y al revés, analizamos como en la prácticas de nuestra vida cotidiana nos apropiamos, transformamos, resignificamos o incluso subviertimos tales productos.

Pero además, la conversación presenta perfectamente el tema de esta charla. Como habéis observamos, en ella aparecen una vendedora y una clienta en una tienda de electrodomésticos. Están discutiendo sobre la soja. La cliente desea saber si la soja es transgénica o no. Y exige un mecanismo, concretamente una etiqueta que la identifique. La vendedora intenta convencerla que toda la soja que se vende en Barcelona es igual, y que no importa si está etiquetada como producto biológico o no. Esta conversación, absolutamente cotidiana, habitual, recurrente en nuestro día a día pone de manifiesto un tema que a nosotros nos interesa en extremo: los alimentos, la alimentación, son una caja negra que recientemente se ha abierto.

En el marco de los estudios sociales de la ciencia y la tecnología es habitual utilizar la expresión caja negra para referirse a la relación entre innovación tecnocientífica y sociedad o cultura. La expresión proviene de la cibernética. Aquí se utiliza para hablar de la parte de un sistema o de todo un conjunto de órdenes que es demasiado complejo para referirlo continuamente en los esquemas explicativos, lo que se hace es asignarle una sigla o denominación breve y advertir que es una caja negra, es decir, que se advierte que bajo esas siglas hay algo que es soslayado por comodidad en las explicaciones. 
Pues bien, cuando en los estudios sociales de la ciencia se habla de que se ha abierto una caja negra se hace referencia a que un proceso, una práctica, una tecnología que utilizábamos de manera acrítica, automática, dando por sentado su sentido y funcionamiento, ha entrado en una espiral de cuestionamiento. Se discute, se analizan sus componentes, se hacen transparentes los procesos implicados en la misma, se pide información sobre su funcionamiento, etc. $Y$ los alimentos, precisamente, constituyen una caja negra que se ha abierto con fuerza en la última década. Los alimentos eran cajas negras sobre los que casi nunca pedíamos noticia de su origen, proceso de elaboración, etc. Aunque bien es verdad que siempre ha habido una pequeña preocupación por conseguir alimentos naturales, etc., el debate sobre los alimentos no se hace popular, no cobra fuerza hasta que dos operadores abren de par en par esta caja.

En primer lugar tenemos las crisis alimentarias, me refiero al problema de las vacas locas y la fiebre aftosa. A partir de estos dos elementos se ha generado mucha información sobre qué se hace con los animales, cómo se manipulan sus despojos, cómo esto puede afectar la salud del consumidor, etc. De hecho, en plena crisis de las vacas locas los políticos recomendaban un cambio en una antigua práctica de cocina y la ministra pedía a las amas de casa que no hiciesen el caldo con huesos de vaca.

En segundo lugar tenemos los alimentos modificados genéticamente, es decir los alimentos transgénicos. Éstos son una de las principales biotecnologías que encontramos en nuestra vida cotidiana, junto con productos farmacéuticos, y la prensa los ha presentado mostrando las extrañas características que pueden adquirir y advirtiendo de supuestos peligros y riesgos. Así, los medios de comunicación hablan de la elaboración de un Tomate-pez, una zanahoria-luciérnaga, etc.

Entre otras cosas, uno de los efectos de tal presentación es que los procedimientos de elaboración de muchos de nuestros alimentos que antes eran poco interrogados, eran algo implícito, asociado al mismo alimento, ahora son permanentemente cuestionados, pedimos información, e información fidedigna sobre los mismos, y no nos conformamos con respuestas generales, las asociaciones de consumidores y movimientos ecologistas piden detalles técnicos y precisos.

Pues bien, una de las dimensiones que aparecen en este debate, un elemento importante en este proceso de descajanegrización de los alimentos, y lo hemos visto en los recortes de prensa y da sentido a la conversación que hemos leído hace un momento, es el riesgo. ¿Qué puede pasar si me como un tomate transgénico?, ¿afectará a mi salud? ¿lo hará a largo plazo, a corto? ¿lo hará en mi descendencia? Este tipo de preguntas siempre gravitan alrededor de los alimentos transgénicos y su implementación masiva.

\section{Riesgo}

La noción de riesgo siempre ha estado presente, de alguna manera, en toda la reflexión sobre los productos científicos y las innovaciones técnicas. Me gustaría hacer un pequeño paréntesis y detenerme un instante en este concepto.

Si se revisa la literatura que existe en la investigación académica sobre el riesgo lo primero que sorprende es que no hay una noción o definición unitaria, y aún menos una teoría que estructure este campo de trabajo e interconecte los múltiples resultados de toda la investigación que ha sido 
desarrollada. De un modo muy general, se aprecia que existen tres grandes enfoques, tres enfoques canónicos sobre el tema:

1) Enfoque técnico: Enfoque que predomina en la investigación sobre riesgo que desarrollan técnicos, empresa privada y administración pública. Se presupone que el riesgo es una propiedad objetiva de los sucesos y las actividades que implican tecnología, con unas probabilidades concretas de darse. Se busca desarrollar un mecanismo que permita establecer una medida universalmente válida para el riesgo con ayuda de la cual puedan establecerse comparaciones entre distintas clases de riesgo. En este enfoque también se presupone que realizando tal cosa se conseguirá obtener un criterio racional de aceptabilidad de los distintos riesgos de acuerdo con su probabilidad y las consecuencias asociadas. Del comercio y de la literatura de la teoría de la decisión se recupera una fórmula que establece que $r=p \times$ m Riesgo es igual al producto de la probabilidad y de la magnitud del daño.

Esta formulación presenta dos graves limitaciones:

a.) En primer lugar, la fórmula sólo opera siempre que pueda determinarse la probabilidad del acontecimiento que produce el daño y la magnitud de éste de acuerdo con una medida cuantitativa.

b.) En segundo lugar, no se ha desarrollado una media unitaria y no problemática para los distintos tipos de daño, no hay una escala unidimensional. El daño se valora de muy diversas maneras.

2) Enfoque psicológico: En éste preocupa la percepción pública del riesgo. Este enfoque parte de una discrepancia constatada entre lo que técnicamente es estimado como un riesgo aceptable y lo que el público está realmente dispuesto a aceptar. El riesgo es una representación cognitiva o estado mental de agentes individuales que tienen grados de aceptabilidad de riesgo vinculados a los contextuales culturales, a las creencias que se manejan o disposiciones comportamentales. Se analizan las variables que influyen individualmente en la percepción y valoración del riesgo, se busca entender cómo las personas evalúan el riesgo en situaciones particulares. En este enfoque se acepta la naturaleza multidimensional del riesgo, en ese sentido va más allá del enfoque técnico.

A título informativo se pueden citar algunos resultados dentro de este enfoque:

- Los riesgos voluntarios se aceptan mejor que los involuntarios. Por ejemplo, se acepta más el consumo de hamburguesas que el uso comercial de organismos modificados genéticamente.

- Los riesgos que se pueden controlar se aceptan mejor. Por ejemplo, se percibe mayor riesgo en el volar que en el conducir.

- Los riesgos de las nuevas tecnologías se perciben como mayores que los asociados a las antiguas. Así, la minería se percibe con un riesgo menor y más controlado que las centrales nucleares.

- Los riesgos donde los daños aparecen con cierto retraso en el tiempo se aceptan mejor que los que implican daños inmediatos. Por ejemplo, se tolera y acepta mejor el consumo de tabaco que la conducción.

- Se percibe con mayor intensidad los riesgos generados por actividades cercanas espacialmente, y se difuminan o desdibujan los de las remotas. Esto permite entender que no aceptemos de buen grado la instalación de ningún tipo de artefacto industrial en las 
cercanías de nuestra vivienda, pero que entendamos que su instalación es necesaria y debe hacerse en otro lugar.

- Se perciben mejor los riesgos donde el daño es reparable o compensable.

- Se perciben mejor los riesgos de pequeña escala, aunque sean más habituales y abundantes que los que provocan daños a gran escala.

Ni que decir tiene que tales planteamientos pueden ser complementarios del anterior enfoque.

3) Enfoque sociológico: El riesgo no es conceptualizado ni como propiedad objetiva ni como propiedades subjetivas que dependen de cómo sean cognitivamente los individuos. El riesgo es una construcción social que depende de factores socioculturales vinculados a estructuras culturales. Construcción recoge en un sentido amplio conceptualizar el riesgo como explicación social, conocimiento cultural, fenómeno, orden conceptual, etc.

El riesgo es una construcción convencional, varía en las distintas estructuras culturales y posee función en ellas, permite una distribución de culpa y responsabilidad, permite también la movilización social o la adaptación de la conducta individual a pautas colectivas. Se analiza qué factores permiten que puntos de vista respecto a riesgos resulten dominantes en grupos sociales dados, o bien que se produzcan contradicciones y polarizaciones.

Lo más interesante de este enfoque es que la experiencia del riesgo no aparece ligada a la experiencia directa del individuo, depende de intereses colectivos o posiciones sociales. En este enfoque el fenómeno de la comunicación del riesgo, por ejemplo, es fundamental. Si el individuo no lo experimenta directamente lo hace de manera vicaria, a través de la prensa, el gobierno, la ciencia, etc. Tal comunicación crea valores y actitudes frente al riesgo. La noción de riesgo no se basa en una evidencia empírica o en razones prácticas, sino que está construida culturalmente, de modo que, en cada contexto social, se destacan unos riesgos y se ignoran otros. Por tanto, no son los individuos de manera aislada y personal los que realizan coherentemente las elecciones que maximizan sus ganancias esperadas o minimizan sus pérdidas... se elige o no correr un riesgo atendiendo a bloques culturales e ideológicos que se habitan y detentan. En rigor, desde esta perspectiva, en lugar de riesgo hay que hablar de un riesgo, de éste riesgo, de aquél, del otro, en definitiva, de riesgos concretos.

Me interesa enfatizar un punto. Un riesgo es ante todo un objeto cotidiano. Mas no es un objeto material como la mesa o la silla, ni un objeto categorial puesto que varía, cambia, etc. Es un objeto definido, dependiente del contexto en el que se elabora tal definición. Formar una creencia sobre un riesgo es un acto cognitivo y ejecutivo. Identificar un riesgo es también valorarlo, pero identificar un riesgo es, del mismo modo, crearlo, mostrar sus límites, perfilar las consecuencias dañinas que puede tener su suceso. En suma, riesgo es una noción que da sentido a un acontecimiento estableciendo un marco conceptual, un marco que recoge otros conceptos, por ejemplo, el de seguridad, decisión, imputabilidad, daño, etc. y que está siempre circunscrito a un contexto histórico y sociocultural. Riesgo es una manera descriptiva y normativa, al mismo tiempo, de conferir inteligibilidad a un acontecimiento. Es un movimiento que atrapa la dimensión cognitiva, porque tiene efectos en el pensamiento de los individuos, la física, atrapa a las cosas en una rejilla de inteligibilidad, y atrapa las situaciones, porque les da límites, forma y propiedades en un único continuum, en un mismo plano. Por tal razón se afirma que el riesgo es un patrón cultural. 


\section{Tecnociencia y riesgo}

Históricamente el impulso principal para investigación del riesgo, el llamado análisis del riesgo o evaluación de riesgo procede del desarrollo civil de la energía nuclear en los años sesenta y setenta. Anteriormente era un marco de trabajo restringido y vinculado académicamente a la teoría de la decisión y la economía teórica, sin gran interés público y utilizado sólo en ámbitos del comercio y la administración. Pero como he dicho, el desarrollo de la energía nuclear volvió a impulsar el interés por esta temática.

En esta época es muy importante el estudio de Charles Perrow (1984) Normal accidents: living with high-risk technology. En este trabajo se muestra cómo plantas nucleares, sistemas de control aéreo, superpetroleros, plantas petroquímicas o misiones espaciales constituyen tecnologías complejas que por sus características intrínsecas incorporan la inevitabilidad de los accidentes, suponen operar con la noción de "catástrofe normal", o dicho de otro modo, normalizan la posibilidad del accidente. El accidente en tales complejos, no debe atribuirse a factores humanos o inesperados, la propia estructura de la tecnología incorpora ese accidente, la catástrofe es una condición del sistema de acción que suponen tales tecnologías. Éstas tecnologías no desarrollan procesos lineales que puedan ser descritos por completo y planificarse cuidadosamente con detalle. La complejidad de la estructura garantiza que no se puede anticipar toda la interacción y derivación de funcionamiento en todos sus elementos. El más mínimo fallo puede producir un efecto en cascada con consecuencias que afectan a toda la estructura y generan un curso de acción inesperado y un colapso general. En tales tecnologías no importa cuánto se mejore la seguridad, el accidente está incorporado en la estructura misma de la tecnología, el riesgo es constitutivo de estos sistemas sociotécnicos. Según este autor, la tecnología que define nuestro presente plantea una paradoja: si se intenta aumentar la seguridad del sistema para prevenir los accidentes o fallos que sabemos están incorporados, aumentamos, a su vez, la complejidad de la estructura y los accidentes se tornan más probables e incontrolables. Esa es la paradoja con la que tendría que lidiar una sociedad altamente tecnologizada como es la nuestra.

La principal crítica argüida contra los trabajos de Perrow consiste en mostrar cómo éstos presuponen una especie de autonomía de la tecnología. Tal supuesto es falaz, la tecnología es inherentemente social y los agentes sociales pueden modularla, abandonarla, los sistemas siempre presentan cierta flexibilidad de trayectoria y se pueden desechar. No estamos abocados inevitablemente a nada.

En la actualidad, el riesgo es un tema tan importante que se utiliza para caracterizar ese fenómeno de cambio social que denominamos globalización. En ese sentido ha cobrado mucha fuerza la propuesta de un grupo de sociólogos (Beck, Giddens...) que caracterizan nuestro presente, la globalización, como sociedad del riesgo.

Me gustaría mostrar los principales rasgos de la misma para llamar vuestra atención sobre un aspecto muy concreto.

La sociedad del riesgo se caracteriza por lo siguiente:

1. Nuestro presente es una ruptura con el pasado en la medida en que la tecnología de alto riesgo ha creado riesgos hasta ahora insospechados.

2. Éstos hacen referencia a catástrofes que pueden adquirir dimensiones gigantescas, pueden darse en cualquier parte del globo gracias a la universalización de la 
tecnociencia y sus consecuencias, y suponen más una distribución de peligros y males (distribución del riesgo) que de bienes y riquezas.

3. De este modo, la vida cotidiana se llena de decisiones arriesgadas, se implementa una gestión cotidiana del riesgo, tomamos muchas decisiones, cada día, relacionadas con riesgos de algún tipo, el riesgo sustituye a las certezas tradicionales.

4. Existe mucha información sobre riesgo, hay polémicas públicas...

5. Por tanto, el riesgo es un elemento que forma parte de muchas agendas políticas.

6. Y es la clave de inteligibilidad en la producción de una gran cantidad de conocimiento especializado

Me gustaría llamar vuestra atención sobre el hecho de que la noción de "sociedad del riesgo" profundiza, lleva hasta sus últimas consecuencias las tesis de los estudios previos de Perrow. Se señala una sociedad basada, estructurada, articulada gracias a la tecnociencia. Se afirma que nuestro presente está definido por la dimensión tecnocientífica y se establece una conexión directa y casi inmediata entre tecnociencia y riesgo. Si algo es la sociedad del riesgo, es una sociedad tecnocientífica, y su condición de acción es la posibilidad de la catástrofe.

Pero a pesar del debate que estas tecnologías levantan y de las protestas de ciertos grupos y movimientos sociales, lo cierto es que son otras las tecnologías que pueblan nuestra vida cotidiana. Dos de las más importantes son las tecnologías de la información y la comunicación (TIC's) y las biotecnologías, ya sea en su expresión farmacéutica o en el ámbito de los alimentos. El análisis de la imbricación entre las tecnologías de la información y la comunicación y nuestras prácticas cotidianas ha llevado a los autores que formularon el concepto de sociedad del riesgo a modificarlo levemente, a hablar concretamente de sociedad del riesgo global. Las TIC's, su papel en el control del armamento, de los mercados bursátiles, etc., permite plantear la idea de un accidente singular que al mismo tiempo colapse globalmente una realidad. Por ejemplo, una fallida bursátil en Asia puede colapsar todo el mercado económico. Esta idea de un accidente global que quiebra toda una dimensión es la nueva acepción, el nuevo matiz que recibe la idea de riesgo. La relevancia de semejante redimensionamiento del riesgo es el anclaje tan importante que adquiere en la vida cotidiana. La sociedad del riesgo global es una sociedad en la cual todavía se potencia más la convivencia con la catástrofe.

La tesis que quiero compartir y discutir con vosotros/as es muy sencilla. Me gustaría mostrar que la biotecnología es otro tipo de producto tecnocientífico, importante en nuestra cotidianidad, y que se suma a las tecnologías de la información como elementos que predican de un riesgo global. Pero, además, las biotecnologías, y hablaré más concretamente, de los alimentos transgénicos, introducen una manera de pensar el riesgo hasta ahora desconocida. Es lo que se puede llamar riesgo virtual.

\section{OMG's como riesgo global:}

Que los alimentos transgénicos $u$ organismos modificados genéticamente pueden generar un accidente singular que colapse una totalidad de cosas, una parcela de la realidad, es algo que se intuye con relativa facilidad. Aquí tengo algunos ejemplos que van en esa dirección: 
Una importante relaciones públicas de una gran empresa multinacional de biotecnología afirma:

- Entrevistador: Usted habla como si sus innovaciones fuesen más perfectas que la propia naturaleza, realmente cree que esto es así o es sólo parte del marketing ?

- Entrevistada: Sin ninguna duda son más precisos, la naturaleza lo hace muy bien, nosotros lo que hacemos es mejorarla... si mejoras algo que ya es muy bueno... pues el resultado es excelente...

Las biotecnologías trabajan, gestionan la vida misma, inciden en la naturaleza, cualquier catástrofe derivada de ellas impacta de lleno en la vida misma, el riesgo que implican las biotecnologías tiene que ver con esa cosa tan amplia y a la vez tan concreta que es la vida misma.

En este otro ejemplo hablan científicos:

"El gen responsable de la esterilización es el gen TERMINATOR. El tema es la producción de nuevas semillas que esterilicen su propia descendencia. ¿Cómo se ha hecho esto? Se introduce en el ADN de la planta un gen esterilizador, ehhh... se le llama normalmente Terminator... la planta crece y el gen se activa al cabo de un año, creo... bueno, más o menos, los efectos son en la generación posterior de la planta... nace estéril. Finalmente la planta muere sin descendencia... Parece terrible... pero tiene utilidades agrícolas... si se combina con otras plantas, bueno, no sé..."

"De esta manera, con el cruce entre un tomate y un pez, por ejemplo, se rompen los límites entre lo que es natural y lo que es artificial. Se cruza el gen de un vegetal con el de un animal. Tenemos... un organismo fruto de una combinación que rompe las clasificaciones clásicas de la naturaleza... Un tomate con un gen de pez es sólo un vegetal o algo más?? No sé, la verdad... es vegetal o animal?? Ni idea, es una transformación global de la naturaleza que no sé..."

“(...)Vamos a ver por ejemplo cuáles son los riesgos que hemos pensado para la salud, los cultivos con genes resistentes a antibióticos (...)esta resistencia se puede transmitir a poblaciones bacterianas de animales domésticos (...) pero también en las aguas residuales, al medio ambiente, este gen podría ser absorbido por bacterias y de aquí podría pasar la resistencia a este antibiótico, podría pasar al rebaño y de allí a las personas, en principio puede pasar, dicen que es muy poco probable pero tenéis que pensar en la cantidad ingente de bacterias de células con este gen."

Habla, de nuevo, la relaciones públicas:

"Los alimentos transgénicos han... digamos conectado, relacionado lo que no había hecho ninguna tecnología. Se generan complejos de empresas multinacionales, los alimentos son producidos y comercializados por empresas multinacionales. Estas empresas reinvierten sus beneficios en investigación... como por ejemplo plantas que producen plásticos... que luego nos beneficia a todos... Se implementan programas de bioprospección donde se recogen plantas por todo el mundo, así si desaparecen se conservan sus semillas... esto también beneficia a la humanidad, en los programas participa la FAO (Organització de les Nacions Unides per l'Agricultura i l'Alimentació) y la OMS (Organització Mundial de la Salut) que intervienen en la 
evaluación de la seguridad de los alimentos transgénicos, crean normes y principio para su regulación... también la OCDE (Organització Per la Cooperació i Desenvolupament Econòmic) y la PVD (Països en Vies de Desenvolupament) que se relacionan con ONGs preocupadas por el hambre en el mundo... los genes son como una materia prima para una nueva economía... por eso la Organización Mundial del Comercio también dice la suya... estamos ante el oro verde, las patentes son caras... este engranaje es muy, pero que muy complejo, si falla un elemento todo se puede venir abajo, se pueden provocar retrasos de años en el desarrollo de una patente, se cierran laboratorios... bueno, se hunden proyectos enteros..."

Habla un científico: Dr. George Wald, profesor Emeritus en Biología de la Universidad de Harvard y Premio Nobel en Medicina.

"Todo esto es demasiado grande y está pasando demasiado rápidamente. Y el problema central sigue sin ser considerado. Probablemente sea el problema ético más grande al que se enfrenta la ciencia. Nuestra moralidad hasta ahora ha sido proseguir sin restricción alguna para aprender todo lo que podemos sobre la naturaleza. Re-estructurar la naturaleza no era parte del trato."

\section{OMGs como riesgo virtual}

¿Qué quiero decir con la expresión riesgo virtual? ¿Qué aporta la palabra virtual a la noción de riesgo? ¿Cómo lo cualifica, de qué manera matiza o cambia su significado? Primera aclaración: virtual no quiere decir posible. Hablar de riesgo posible, como se verá inmediatamente, es un pleonasmo, la idea de riesgo ya incorpora que es una posibilidad.

Para entender el significado de virtual, tal y como lo utilizo aquí, necesito una referencia, un autor que proviene de la tradición filosófica. Me refiero al filósofo Henri Bergson. Uno de los temas centrales de su obra fue la vida, más concretamente, el avance creativo de la vida. Para hablar de este movimiento, que es la realidad misma que nos envuelve, distinguió entre posible y virtual como dos condiciones de la realidad. Ni lo posible ni lo virtual se oponen a la idea de realidad, ambos son formas de esta realidad. La diferencia estriba en que lo posible es una copia de lo real. Lo posible representa y se parece a lo real. La posibilidad no es más que una imagen especular de la realidad. Lo virtual, sin embargo, es una parcela de lo real que se diferencia de lo actual, lo virtual es una potencia, tiene la característica de que cuando se actualiza siempre lo hace introduciendo diferencia. Por tanto, lo virtual no es representable, como si lo es lo posible. En esto Bergson estaba trabajando con la etimología de la palabra virtual, es decir, con la idea de Virtus, que indica una tendencia, una línea de actualización abierta y siempre incompleta. Lo virtual tiene la capacidad de sorprender, lo posible no.

Pues bien, hasta ahora, en los trabajos sobre riesgo, los trabajos que asocian el riesgo a las tecnologías complejas como la energía nuclear o a las tecnologías como las TICs, cuando se piensa el riesgo se piensa con este sentido de posibilidad, de copia de una realidad, que no se ha dado, pero que se puede dar. Veamos, la palabra riesgo alude a una contingencia próxima, la contingencia no es más que la posibilidad de que algo suceda o no. Pero tenemos una idea, una copia, una representación, aunque no sea completamente perfecta, de lo que puede acaecer. El riesgo no es más que una manera de pre-ver, pre-observar, de anticipar el futuro, de definirlo, si se quiere, de colonizarlo. El riesgo es una incertidumbre calculable, representable, comunicable. Cuando hablamos 
de riesgos en una central nuclear tenemos una representación, un modelo de lo que puede ocurrir. Cuando hablamos de riesgo global también tenemos una imagen de que se puede esperar. En todas estas tecnologías somos capaces de esa pre-visión, de ese diseño del futuro.

De hecho, una de las razones por las que tecnociencia y riesgo son don conceptos tan estrechamente relacionados, conectados, es que esa relación no es más que el diseño, la definición de un orden social que implica una planificación muy concreta del pasado y del futuro. La tecnología genera riesgos que antes no existían, por tanto introduce un nuevo presente y ante tales riesgos futuros hemos de prepararnos, se diseña el futuro.

Pues bien, la biotecnología, en tanto que trabajo, operación sobre la vida incorpora un nuevo tipo de riesgo. Recuperando esta cualidad que Bergson daba al poder creador de la vida, podemos hablar de que las biotecnologías incorporan un riesgo virtual. El riesgo virtual es una incertidumbre incalculable, lo más importante es que es incomunicable. Estamos ante posibles transformaciones, catástrofes, accidentes, lo que sea, que no podemos pre-ver, no podemos anticipar, no podemos representar, no podemos imaginar. Se pueden aventurar hipótesis, pero puesto que la vida tiene ese componente de creatividad, de virtualidad, siempre nos sorprenderá. El consumo de alimentos transgénicos abre transformaciones, pero no sabemos qué transformaciones. Sabemos que pone sobre la mesa un riesgo, pero no la forma de éste.

Afirma un científico:

“(...) qué pasaría si se introdujera un maíz que también fuera resistente al glifosato, esta pregunta... qué pasaría a largo plazo, cuál seria el impacto de tener hectáreas y hectáreas de Argentina plantadas con un sistema de glifosato y maíz transgénico resistente al herbicida..., esta pregunta crucial no hay nadie en Argentina, nadie que se la haga... La Comisión de Bioseguridad toma decisiones respecto a... bueno, sobre pequeñas pruebas de campo de diversos sitios pero nadie mira el cuadro de lo que es ya... estoy hablando de la producción agrícola, estoy hablando de efectos inesperados, de lo que pasa cuando tienes... se está promoviendo un modelo de bioseguridad super a corto plazo, nadie mira el largo plazo (...)"

Este riesgo virtual aparece muy claramente en las biotecnologías cuando se introduce la variable tiempo en su análisis. Una manera habitual de aproximarse al debate sobre los alimentos transgénicos es mediante los interrogantes: qué, dónde, cuánto... pero si añadimos la pregunta cuándo, el panorama de la discusión cambia. Cuando el tiempo se añade a esta reflexión, las transformaciones genéticas ya no son sólo una cuestión de riesgo global como mencionaba antes, es decir, de movilidad del gen sobre el espacio y la materia -su incorporación a otras especies, las relaciones institucionales que crea, etc. Cuando el tiempo se añade aparece el riesgo virtual, sabemos que habrá transformaciones, que pueden ser definitivas, para siempre, pero no sabemos qué transformaciones tenemos enfrente.

La evidencia acumulada durante los últimos veinte años nos dice que:

- Ningún gen opera aisladamente

- El desarrollo genético está ligado a la relación con el medio

- Esa relación puede facilitar mutaciones 
- Los genes se pueden transferir horizontalmente, es decir, fuera del organismo original que lo contiene

- El comportamiento de un organismo alterado genéticamente en su ambiente no se deduce o predice de sus condiciones contraladas en el laboratorio

La biotecnología es una tecnociencia peculiar. Es demiúrgica. Igual que la figura de cualquier dios mítico se define porque aleja al ser humano del conocimiento exacto del futuro, las tendencias que se abren con tal tecnociencia nos arrojan a un presente que no puede definir su futuro. La posibilidad del error desaparece del horizonte de estas tecnologías en la medida en que cualquier error es irreversible, supone una transformación y una cadena de transformaciones asociadas, que no pueden deshacerse.

El siguiente cuadro recoge la evolución de los planteamientos de la biología desde los planteamientos de Mendel hasta la actualidad:

\begin{tabular}{|c|c|c|}
\hline Dogma Mendeliano & $\begin{array}{l}\text { Dogma de la biología molecular } \\
1950-1970\end{array}$ & El genoma fluido \\
\hline $\begin{array}{l}\text { Els caràcters d'un organisme } \\
\text { estan determinats per factors } \\
\text { unitaris estables anomenats } \\
\text { gens, cada un dels quals } \\
\text { succeeix dos cops, en dos al·lels } \\
\text { (variants d'un gen particular) i } \\
\text { que poden ser iguals o diferents } \\
\text { entre si. } \\
\text { Cada organisme conté un gran } \\
\text { nombre de gens. } \\
\text { Els gens passen sense canvis } \\
\text { d'un progenitor al fill per mitjà de } \\
\text { les cèl·lules germinals. } \\
\text { Cada cèlllula germinal conté una } \\
\text { sola còpia de cada gen de } \\
\text { manera que la combinació } \\
\text { precisa de gens variarà a l'atzar } \\
\text { d'una cèl·lula germinal a una } \\
\text { altra. }\end{array}$ & $\begin{array}{l}\text { L'ADN (i en alguns virus ARN) } \\
\text { és el material genètic. } \\
\text { La informació genètica flueix de } \\
\text { l'ADN a l'ARN i d'allí a les } \\
\text { proteïnes mitjançant un codi } \\
\text { genètic de triplets. } \\
\text { La seqüència de bases de l'ARN } \\
\text { transcrit i després traduït en una } \\
\text { proteïna és una còpia } \\
\text { complementària fidel de l'ADN } \\
\text { que codifica la proteïna. } \\
\text { Una proteïna és especificada } \\
\text { per un gen, que és una } \\
\text { seqüència contínua d'ADN. } \\
\text { La seqüència de bases en el } \\
\text { gen correspon exactament a la } \\
\text { seqüència d'aminoàcids de la } \\
\text { proteïna codificada. }\end{array}$ & $\begin{array}{l}\text { Transcriptassa inversa en els } \\
\text { retrovirus }{ }^{2} \text { i en eucariotes. } \\
\text { Gens superposats: }{ }^{3} \text { un gen } \\
\text { codifica dos proteïnes. } \\
\text { L'ADN mitocondrial i el d'alguns } \\
\text { protozous ciliats és diferent a } \\
\text { l'universal. } \\
\text { Exons, regions codificadores, i } \\
\text { Introns, regions no } \\
\text { codificadores, aporten } \\
\text { complexitat al sistema. } \\
\text { Gens silenciats: citosines } \\
\text { metilades }{ }^{4}, \text { ADN transcrit que és } \\
\text { descompost, inactivació } \\
\text { aleatòria del cromosoma X. } \\
\text { ADN “basura": hi ha cops en que } \\
\text { fins un } 99 \% \text { de l'ADN no té } \\
\text { funció coneguda. }\end{array}$ \\
\hline
\end{tabular}

${ }^{2}$ Descoberts per Howard Jemin i David Baltimore a començaments dels 70's.

${ }^{3}$ Sanger el 1977 en descobreix en el bacteriòfag 0174.

${ }^{4}$ La metilació s'hereta, és un exemple d'herència epigènica o de caràcters adquirits. 


\begin{tabular}{|c|c|c|}
\hline Dogma Mendeliano & $\begin{array}{l}\text { ogma de la biología molecular } \\
950-1970\end{array}$ & El genoma fluido \\
\hline $\begin{array}{l}\text { Quan les cèl·lules germinals } \\
\text { s'uneixen durant la fertilització, } \\
\text { el zigot resultant (ou fecundat) } \\
\text { tindrà de nou dos al·lels de cada } \\
\text { gen. } \\
\text { La separació d'al·lels i la } \\
\text { recombinació entre al·lels de } \\
\text { diferents gens durant la } \\
\text { reproducció expliquen les } \\
\text { semblances i diferències entre } \\
\text { generacions successives. } \\
\text { S'ha de distingir la constitució } \\
\text { genètica d'un organisme, el seu } \\
\text { genotip, dels caràcters } \\
\text { expressats, el fenotip. } \\
\text { L'acció d'un al·lel pot ser } \\
\text { dominant o recessiva respecte } \\
\text { d'un altre segon que s'expressi o } \\
\text { no en combinació amb l'altre } \\
\text { al·lel. }\end{array}$ & $\begin{array}{l}\text { El codi genètic és universal. } \\
\text { La seqüència de triplets de } \\
\text { bases d'un gen es llegeix en una } \\
\text { direcció, sense superposició i } \\
\text { només en un marc de lectura } \\
\text { correcte. } \\
\text { L'ADN de la majoria de les } \\
\text { cèl-lules resten constants durant } \\
\text { el desenvolupament; només els } \\
\text { gens expressats són diferents } \\
\text { entre diferents tipus de cèl·lules. } \\
\text { Les modificacions en les } \\
\text { característiques de les cèl·lules } \\
\text { somàtiques induïdes per } \\
\text { l'ambient no afecten l'ADN i no } \\
\text { poden heretar-se. }\end{array}$ & $\begin{array}{l}\text { funció coneguda. } \\
\text { Transpons }{ }^{5} \text { : gens "saltarins" } \\
\text { elements genètics mòbils. } \\
\text { Retrotranspons: transpons amb } \\
\text { transcripció inversa per moure's } \\
\text { i duplicar-se. } \\
\text { Pseudogens: seqüències } \\
\text { codificadores no funcionals. } \\
\text { Transferència horitzontal de } \\
\text { gens: bactèries i virus fan de } \\
\text { pont en el traspàs de gens entre } \\
\text { animals, plantes, algues, fongs i } \\
\text { protozous. } \\
\text { Amplificació i contracció de } \\
\text { gens: és generat com a resposta } \\
\text { fisiològica en certes línies } \\
\text { cel-lulars sotmeses a } \\
\text { determinades drogues, insectes } \\
\text { exposats a insecticides, herbes } \\
\text { a herbicides, en l'adquisició de } \\
\text { resistència a antibiòtics... }\end{array}$ \\
\hline
\end{tabular}

La nueva genética invalida totalmente la idea determinista de que un gen controla una característica y que si transferimos el gen transferimos la característica indefinidamente a las futuras generaciones, la ingeniería genética no es un proceso simple y lineal. Los genes transferidos pueden tener efectos secundarios en modo alguno esperados. Un caso ilustrativo de los riesgos virtuales de la biotecnología es una serie de experimentos en los que ratas alimentadas con patatas modificadas con lectina de campanilla blanca sufrían graves daños en muchos órganos, incluido el cerebro, daños en el sistema inmunológico y signos de infección viral. Tales efectos no aparecían en un grupo control alimentado con patatas no transgénicas inyectadas con la misma sustancia.

Otros ejemplos:

- La polinización cruzada entre plantas transgénicas y parientes silvestres hace que los genes se esparzan por el ambiente. En el caso de planteas modificadas resistentes a herbicidas pueden convertir malas hierbas en maleza resistente a los herbicidas

\footnotetext{
${ }^{5}$ Descoberts per la premi Nobel 1983 Bàrbara McClintock.
} 
- Se subestiman los efectos de las bacterias transgénicas liberadas en el suelo. Hay un caso de una bacteria (Klebsiella planticola) modificada para producir más etanol, el etanos afectó a otros organismos importantes en el reciclaje de nutrientes importantes para el crecimiento de otras plantas.

- La transferencia genética horizontal y la recombinación es otra fuente de riesgo virtual. Así se pueden difundir los genes a especies no relacionadas. Así pueden aparecen nuevos virus o bacterias. Por ejemplo, en Inglaterra está prohibido el trigo de Ciba-Geigy porque contiene genes de tolerancia a la ampicilina.

“(...) los genes responden a la fisiología del organismo y requieren una ecología estable y equilibrada para mantener su viabilidad. La agricultura orgánica se basa en una ecología que depende de una comunidad diversa de organismos saludables y libres de elementos agroquímicos." (Mae-Wan Ho)

La biotecnología se basa en diseñar vectores artificiales que puedan atravesar fácilmente las barreras de las especies. Esa transversalidad ontológica es una acción sobre la vida misma, por tanto, es inherentemente impredecible, está plagada de riesgos, sabemos que habrá contingencia, transformaciones, catástrofes, pero no acertamos a elaborar un esquema comunicable de las mismas, es por eso, también, riesgo virtual.

Para finalizar, y ya daros la palabra sin más demora, me gustaría volver a la conversación con la abría esta charla. En ella observábamos, sobre todo, que este riesgo virtual ha llegado a nuestra cotidianidad, lo gestionamos a menudo, junto a otros muchos riesgos, y ha permitido abrir esa caja negra que es la alimentación. Pues bien, en esta implementación en la cotidianidad del riesgo virtual que implican las biotecnologías también apreciamos, paradójicamente que este riesgo virtual puede ser un fenómeno positivo. Tradicionalmente cuando se trata el fenómeno del riesgo se lo conceptualiza como un fenómeno negativo, pues bien, el riesgo virtual puede conceptualizarse como fenómeno con una dimensión de positividad importante. Voy a comentar las claves de esta positividad, que nos permitirán pensar en este fenómeno de una manera distinta, como un terreno de juego nuevo y del que se pueden extraer conclusiones interesantes

1. El riesgo es productivo, no alude directamente a daños acontecidos o actualizados, por tanto, puede ser base para la socialización, puede generar comunidad. El compartir riesgos, especialmente en el terreno de las biotecnologías, ha generado grupos colectivos preocupados por la correcta señalización de los organismos modificados genéticamente, etc. Además, ese compartir riesgos es asumir también responsabilidades. Esto devuelve al ciudadano cotas de participación pública y política importantes.

2. El concepto de riesgo virtual invierte la relación entre pasado, presente y futuro. Habíamos visto que en la sociedad del riesgo se rompía con el pasado. Pues bien, dado que el riesgo virtual alude a una incertidumbre incomunicable, sin representación, se mira al pasado para extraer consecuencias y lecciones que de alguna manera suplan esa planificación de futuro. Es lo que han hecho algunos colectivos que han recuperado procedimientos tradicionales de agricultura, elaboración de alimentos, etc.

3. Los juicios sobre el riesgo ni son sólo fácticos ni son sólo de valor, son ambos al mismo tiempo o algo entre los dos. Es decir, son una construcción, una producción de realidad social. 
4. El riesgo y la percepción del riesgo son consecuencias, para muchos autores, de la lógica de control y planificación que impera en la modernidad. La noción de riesgo virtual rompe de alguna manera con tal lógica. Lo que se impone es más una acción en el presente que cierre riesgos virtuales que una definición planificada de acciones futuras. Por tanto, hay una suerte de vindicación de esa acción continuamente presente que es la vida cotidiana. Se privilegia este espacio como terreno de toma de decisiones.

5. Las claves del riesgo virtual son al mismo tiempo locales y globales. Como hemos visto, la biotecnología supone el establecimiento de grandes engranajes en los que participan multitud de actores sociales, institucionales, económicos, etc. Pero al mismo tiempo, la acción de un ciudadano pidiendo una etiqueta, negándose a comprar un producto porque carece de ella, cuestiona, afecta o impacta ese engranaje.

La biotecnología es un tipo de producto tecnocientífico que predica sobre un riesgo muy concreto, el riesgo virtual. Éste se gestiona habitualmente en nuestra cotidianidad. Y presenta evidentemente una faz negra, rayana en lo apocalíptico pero también un aspecto positivo, productivo. Me gustaría acabar esta charla leyendo unos versos de un poeta alemán que el filósofo Martín Heidegger cita en su ya texto canónico titulado "La pregunta por la técnica". Considero que esos versos recogen perfectamente la peculiaridad que manifiesta el riesgo virtual y recogen también exactamente el espíritu ambivalente que subyace en la conversación que hemos leído al principio. Dicen así: "Pero donde hay peligro, crece también lo que salva"

Obviamente, el riesgo virtual encierra una promesa de muerte, mas también una promesa de vida... ¿cuál de ellas se hará efectiva?

Gracias por vuestra atención...

\section{Formato de citación}

Tirado, F. (2003). Riesgo, tecnociencia y biotecnología. Athenea Digital, 4. Referencia. Disponible en http://antalya.uab.es/athenea/num4/tirado.pdf 